\title{
Polarity of Gene Transfer in Caulobacter
}

\author{
By J. D. JOLLICK AND T. Q. TRAN \\ Department of Immunology and Microbiology, Wayne State University School of \\ Medicine, Detroit, MI 48201, U.S.A.
}

(Received 21 May 1975; revised 10 June 1975)

\section{INTRODUCT.ION}

Jollick \& Schervish (I972) presented evidence for genetic recombination in Caulobacter. Both members of the mating pairs were shown to be required for recombination, since lysates of either parent of a positive cross could not effect recombination when mixed with intact cells of the other parent. This observation supports similar findings by Shapiro, AgabianKeshishian \& Bendis (197I), and leads to the conclusion that genetic recombination in this genus occurs by conjugation.

The undirectional nature of gene transfer as described in Escherichia coli $\mathrm{KI} 2$ by Hayes (1952), implied sexuality in bacteria; this was later demonstrated in E. coli by Hayes (1953), Lederberg, Cavalli \& Lederberg (1952), and other investigators (Jacob \& Wollman, I96I), with the discovery and characterization of F factors. Similar F-like factors have been reported in Pseudomonas (Holloway \& Jennings, 1958), Vibrio (Bhaskaran 1964; Datta et al. 1973) and in Streptomyces (Hopwood et al. 1972). Since each of these mating systems exhibited a polarity of gene transfer, it was reasonable to determine if a similar phenomenon existed in the conjugation system of Caulobacter. Experiments similar to those of Hayes, which showed that the viability of only one member of a mating pair is essential to gene transfer, are reported here.

\section{METHODS}

Bacterial strains. Procedures for constructing strains have been previously reported (Jollick \& Schervish, 1972). Streptomycin-resistant (str-r) mutants were selected directly on streptomycin-containing medium. The strains used are listed in Table I.

Media. Complete medium was the peptone-yeast extract (PYE) medium of Poindexter (I964). Streptomycin- or penicillin (Pen)-resistant mutants were selected on PYE medium supplemented with $200 \mu \mathrm{g}$ streptomycin sulphate or penicillin $/ \mathrm{ml}$, respectively. Minimal medium consisted of $(\%, \mathrm{w} / \mathrm{v})$ : glucose, $0.2 ;\left(\mathrm{NH}_{4}\right)_{2} \mathrm{SO}_{4}, 0 . \mathrm{I} ; \mathrm{K}_{2} \mathrm{HPO}_{4}, 0.05 ; \mathrm{KH}_{2} \mathrm{PO}_{4}$, $0.05 ; \mathrm{MgSO}_{4} .7 \mathrm{H}_{2} \mathrm{O}, 0.0 \mathrm{I}$; agar, $\mathrm{I} \cdot 5$. Histidine, methionine and arginine were added to minimal medium where appropriate. The concentration of the amino acid supplements was $2 \cdot 0 \mu \mathrm{g} / \mathrm{ml}$.

Mating procedures. Control matings were performed by mixing $\mathrm{I} \cdot 0 \mathrm{ml}$ of an $\mathrm{I} 8$ to $24 \mathrm{~h}$ PYE broth culture of each partner. The viable titre of each strain was standardized at $\mathrm{I} \cdot 5 \times 10^{8}$ to $3.0 \times 10^{8}$ colony-forming units $/ \mathrm{ml}$ before mixing. All mating mixtures were incubated at $30{ }^{\circ} \mathrm{C}$ for $2.0 \mathrm{~h}$ and then $0 . \mathrm{I} \mathrm{ml}$ of each mixture was spread on solid minimal medium (containing appropriate supplements where required). Each individual member of the cross was tested for reversion.

To test the polarity of gene transfer and identify donor and recipient strains, matings were performed as described above, except that streptomycin $(200 \mu \mathrm{g} / \mathrm{ml}$, final concentration) 


\section{Table I. Caulobacter strains}

\begin{tabular}{|c|c|c|c|}
\hline $\begin{array}{c}\text { Strain } \\
\text { designation* }\end{array}$ & $\begin{array}{c}\text { Proposed } \\
\text { mating type }\end{array}$ & Genotype & Source \\
\hline CBI 5 & Donor & Prototroph & ATCCI 9089 \\
\hline WSI & Donor & asp-I str-s & CBI 5 \\
\hline WS2 & Donor & his-I str-s & CBI 5 \\
\hline ws3 & Donor & asp-2 str-s & CBI 5 \\
\hline WS4 & Donor & his-2 str-s & CBI 5 \\
\hline ws5 & Donor & his-3 str-s & CBI 5 \\
\hline ws 6 & Donor & his-4 str-s & CBI 5 \\
\hline ws9 & Donor & his-5 str-s & CBI 5 \\
\hline WSI 2 & Recipient & met-3 str-s & CBI 5 \\
\hline WSI 8 & Donor & $a s p-I$ str-r & WSI \\
\hline Wsig & Donor & his-I str-r & WS2 \\
\hline Ws2o & Donor & his-3 str-r & ws5 \\
\hline ws25 & Donor & ser-I str-s & CBI 5 \\
\hline Ws26 & Donor & ser-I str-r & WS25 \\
\hline Ws 28 & Donor & trp-2 str-s & CBI 5 \\
\hline ws3o & Recipient & met-3 str-r & WSI 2 \\
\hline
\end{tabular}

* The strain designation CBI5 is the original one of Poindexter (1964), and is retained in this paper; ws designations are those strains isolated by the authors.

was added to the mating mixture and after the mating incubation of $2 \mathrm{~h}$ the culture was centrifuged and the pellet resuspended in fresh PYE broth before plating on the appropriate selective medium.

In a variation of the above, the matings between str-r and str-s strains were performed by our standard mating procedure, then plated on minimal medium and minimal + streptomycin $(200 \mu \mathrm{g} / \mathrm{ml})$.

In all matings the plates were incubated at $30^{\circ} \mathrm{C}$ and checked at 5, 7 and 12 days. Recombinant colonies were counted at $\mathrm{I} 2$ days.

Matings on solid media. Once donor strains were identified it was important to establish the stability of the donor property during storage. Donors that were stored on complete agar slants were periodically streaked on to complete medium and at least 60 isolated colonies picked and transferred to gridded PYE plates which serve as the donor master plates. The recipient strain was grown in PYE broth, and after $24 \mathrm{~h}$ the bacteria were collected by centrifugation and resuspended in distilled water; this suspension was spread uniformly on a minimal plate. The donor master plate was then replica-plated on to the minimal plate spread with the recipient strain. The plates were incubated at $30{ }^{\circ} \mathrm{C}$ and examined at 5, 7 and 12 days for prototroph (recombinant) formation.

\section{RESULTS AND DISCUSSION}

To show the polarity of gene transfer in bacteria one must demonstrate that each parent in a cross does not play an equivalent role in the formation of recombinants. The experiments described here were suggested by those used by Hayes (1952) to show polarity of transfer in $E$. coli. The basic point is that the viability of one parent (the recipient) is necessary for expression of the recombinant genotype whereas the viability of the donor is of no consequence once the act of transfer is accomplished.

Identification of fertile auxotrophic mating strains. We determined from preliminary matings of our auxotrophs that several mating combinations gave consistently high frequencies of recombinant formation and showed very low frequencies of reversion to prototrophy. Auxotroph WSI 2 was one of our better mating auxotrophs. It produced recombinants with 
Table 2. The effect of streptomycin in the mating mixture on recombinant formation with str-r and str-s mating combinations

\begin{tabular}{|c|c|c|c|c|c|}
\hline & \multicolumn{2}{|c|}{ No. of recombinant colonies } & & \multicolumn{2}{|c|}{ No. of recombinant colonies } \\
\hline Cross & $\begin{array}{c}\text { No } \\
\text { streptomycin }\end{array}$ & $\begin{array}{c}\text { Plus } \\
\text { streptomycin }\end{array}$ & Cross & $\begin{array}{c}\text { No } \\
\text { streptomycin }\end{array}$ & $\begin{array}{c}\text { Plus } \\
\text { streptomycin }\end{array}$ \\
\hline WSI $8 \times$ WSI 2 & I 20 & 0 & WSI $\times$ WS30 & 300 & 12 \\
\hline WSI $9 \times$ WSI 2 & 290 & 0 & ws $2 \times$ ws 30 & 210 & 4 \\
\hline WS $20 \times$ WSI 2 & 205 & 0 & ws $5 \times$ ws 30 & 113 & 12 \\
\hline WS $26 \times$ WSI 2 & $20 \mathrm{I}$ & 0 & $w s 25 \times w s 30$ & 433 & 17 \\
\hline
\end{tabular}

several other auxotrophs including WSI, ws2, ws3, ws4, ws5, ws6, ws25 and ws28. Recombinant frequencies ranged from $5 \times 10^{-6}$ to $8 \times 10^{-7}$ recombinants per recipient cell plated.

Mating in the presence of streptomycin. Following the identification of fertile pairs, we made each partner $s t r-r$ and then mated $s t r-s$ and $s t r-r$ combinations of the known fertile pairs in the presence of streptomycin as described above. The $s t r-r$ strains wsi 8 (derived from WSI), Wsi9 (derived from ws2), wS20 (derived from ws5), and ws26 (derived from wS25) produced recombinants when mated with WSI2 in matings without streptomycin (Table 2). Likewise, recombinants were produced when ws30 (str-r derivative of wsI2), was mated with WSI, WS2, ws5 and WS25. When streptomycin was added to the mating mixtures, no recombinants were formed in crosses with wSI 2 (str-s) even though the other partner in the mating was str-r. We did note, however, a relatively low frequency of recombination when ws30 (str-r) was mated with WSI, WS2, WS5 and WS25 (all str-s) in the presence of streptomycin. The number of recombinants formed in these crosses in the presence of streptomycin was reduced to less than $10 \%$ of the control. These data suggest that the viability of WSI 2 , or its str-r derivative w3o, was required for recombinant formation, and the viability of WSI, WS2, WS5 or WS25 was not essential. The exposure of the mating partners to streptomycin for the full $2 \mathrm{~h}$ of the mating incubation could be responsible for the reduction in the number of recombinants recovered from the ws30 crosses seen in Table 2.

Mating followed by recombinant selection on streptomycin containing minimal medium. Matings mixtures of WSI $\times$ WSI 2 , WSI $\times$ WS 30 , WSI $8 \times$ WSI 2 and WSI $8 \times$ WS 30 were incubated for $2 \mathrm{~h}$ then plated on minimal and minimal + streptomycin media. On the minimal medium (control), recombinants were detected in numbers consistent with earlier matings with these strains (Table 3). However, on the streptomycin-containing minimal medium no recombinants could be seen in the WSI $\times$ WSI 2 cross. In the WSI $\times$ WS30 cross the number of recombinants detected represented $3.50 \%$ of those seen with the control, while in the reciprocal cross WSI $8 \times$ WSI 2 the recombinants seen represented only $0.35 \%$ of the control cross. In the crosses where both parents were $s t r-r$ (WsI $8 \times$ ws 30 ) the number of recombinants equalled $8.50 \%$ of the control cross. The results (Table 3 ) again showed that the viability of strain WSI 2 or its str-r derivative was essential to recombinant formation while the viability of the other partner was not.

In both types of experiment the presence of streptomycin reduced the number of recombinants formed, even when two streptomycin-resistant parents were mated. This suggests that streptomycin interferes in some way with mating or recombination, or both. However, in each type of experiment it appeared that wsi2, or its derivative w30, must retain viability. We therefore designated WSI 2 and its derivatives as recipients and WSI and its str-r derivatives as donors.

Test of donor stability. Donor strains wsI, ws6 and ws9 which mated with wsI2 and its 
Table 3. The effect of streptomycin in the selective medium on recombinant formation by str-r and strs- mating combinations

\begin{tabular}{|c|c|c|}
\hline \multirow[b]{2}{*}{ Cross } & \multicolumn{2}{|c|}{$\begin{array}{c}\text { No. of recombinant colonies } \\
\text { on minimal plates }\end{array}$} \\
\hline & $\begin{array}{c}\text { No } \\
\text { streptomycin }\end{array}$ & $\begin{array}{c}\text { Plus } \\
\text { streptomycin }\end{array}$ \\
\hline WSI $\times$ WSI 2 & 300 & $0 . I$ \\
\hline WsI $\times$ ws30 & 341 & $12 \cdot 0$ \\
\hline WSI $8 \times$ WSI 2 & I4I & 0.5 \\
\hline WsI $8 \times w s 30$ & 200 & $17 \cdot 0$ \\
\hline
\end{tabular}

derivatives, were periodically tested for the retention of donor capacity after storage. Strains stored in frozen skim milk showed no detectable loss of the donor property for up to three months. When strain ws9 was stored on solid medium at $4{ }^{\circ} \mathrm{C}$, approximately $50 \%$ of the cells lost the donor property, whereas strains wsI and ws6 did not lose the donor property under these conditions. The tests of the stability of the donor property during storage indicated that most strains designated as donors do retain the property; we have also shown the same stability with several lyophilized strains.

We conclude that unidirectional gene transfer does occur in conjugating strains of Caulobacter.

Note added in proof. In a recent report (Gene transferin Caulobacter crescentus: Polarized inheritance of genetic markers. Genetics 80, I-I I.) Newton and Allebach presented evidence which indicates polarity of gene transfer in Caulobacter. Their evidence includes 'the preferential inheritance of unselected markers from the non-fertile parent', which means the majority genotype of their recombinants is that of the 'non-fertile' or recipient strain. Although our methodology, strains and some of our findings differ, we feel that our report and that of Newton and Allebach confirm the existence of donor and recipient cell types in Caulobacter.

This work was supported by grant IRoI GM 2 I 228 from the National Institute of General Medical Sciences. We thank Ms Rosemarie Klaiber for excellent technical assistance.

\section{REFERENCES}

BHASKARAN, K. (1964). Segregation of genetic factors during recombination in Vibrio cholerae strain 162. Bulletin of the World Health Organization 30, 845-853.

Datta, A., Parker, C. D., Wohlhieter, J. A. \& Baron, L. S. (I973). Isolation and characterization of the fertility factor $\mathrm{P}$ of Vibrio cholerae. Journal of Bacteriology 113, 763-77.

HAYES, W. (1952), Recombination in Bact. coli K12; unidirectional transfer of genetic material. Nature, London 169, I $18-119$.

HaYes, W. (1953). Observations on a transmissible agent determining sexual differentiation in Bacterium coli. Journal of General Microbiology 8, 72-88.

Holloway, B. W.'\& Jennings, P. A. (1958). An infectious'fertility factor for Pseudomonas aeruginosa. Nature, London $181,855-856$.

Hopwood, D. A., Chater, K. F., Dowding, J. E. \& Vivian, A. (1972). Advances in Streptomyces coelicolor genetics. Bacteriological Reviews 37, 37I-405.

JacoB, F. \& Wollman, E. L. (1961). Sexuality and the Genetics of Bacteria, pp. 4I-45. New York: Academic Press. 
JoLLICK, J. D. \& SCHERVISH, E. M. (1972). Genetic recombination in Caulobacter. Journal of General Microbiology 73, 403-407.

LederberG, J., CAVAlli, L. L. \& Lederberg, E. M. (1952). Sex compatability in E. coli. Genetics 37, 720-730.

PoINDEXTER, J. S. (1964). Biological properties and classification of the Caulobacter group. Bacteriological Reviews 28, 23I-295.

Shapiro, L., Agabian-Keshishian, N. \& Bendis, I. (1971). Bacterial differentiation. Science, New York 173, 884-892. 